\title{
A TRANSFORMAÇÃO POLÍTICO-ECONÔMICA DO CAPITALISMO DO FINAL DO SÉCULO XXI: DO FORDISMO À ACUMULAÇÃO FLEXÍVEL ${ }^{1}$
}

\author{
Thiago Augusto Nogueira de Queiroz ${ }^{2}$
}

Para Harvey a data inicial do fordismo se deu no ano de 1914, quando Henry Ford implantou uma jornada de trabalho de oito horas diárias, dando uma gratificação para os trabalhadores da linha automática de montagem de carros. A forma corporativa de organização de negócios já vinha ganhando seu espaço desde o século XIX com a construção das estradas de ferro, as fusões e formações de trustes e cartéis entre as empresas. Ford acrescentou a esses fatores a racionalização de velhas tecnologias, uma rígida divisão do trabalho, colocando os trabalhadores em posição fixa, e com isso obtendo grande produtividade e lucros.

As oito horas de trabalho diários fazia com que os trabalhadores tivessem mais tempo para o lazer e a prática. Essa foi uma das grandes genialidades de Ford que propôs mais renda aos seus empregados e mais tempo livre aos mesmos. Assim, os trabalhadores gastariam toda a renda obtida com o trabalho nos produtos industrializados, no lazer, no turismo, retornando parte dessa renda para o próprio capitalista, aumentando a produção de lucros. Os trabalhadores ganhavam dinheiro suficiente para comprar o produto em que ele próprio fez parte da produção, retornando o salário que ele recebeu para as mãos do empregador.

Mas, muitos empresários, da época, não viam isso com bons olhos, tendo o a linha de produção fordista uma grande dificuldade de disseminação, principalmente nos anos entre guerras. Somente após a crise de 1929, as idéias de um Estado forte para manter a economia estável foi aclamada, sendo as idéias keynesianas aliadas as idéias fordistas. Assim, segundo Harvey a atuação mais forte do Estado levou ao amadurecimento do fordismo.

Assim, após a Segunda Guerra Mundial acontece o auge do fordismo, que passou a ser implantado nos principais países industrializados do mundo, tendo o protecionismo do Estado como aparato de um consumo em massa, garantindo a produção em massa das empresas. Os sindicatos durante no período fordista ganharam considerável poder, tomando iniciativas de

\footnotetext{
${ }^{1}$ Resenha da segunda parte (A transformação político-econômica do capitalismo do final do século XXI) da obra "HARVEY, David. A condição pós-moderna: uma pesquisa sobre as origens da mudança cultural. 19. ed. Tradução de Adail Ubirajara Sobral e Maria Stela Gonçalves. São Paulo: Loyola, 2010”. Atividade da disciplina Geografia Econômica, ofertada pelo Departamento de Geografia (DGE) da Universidade Federal do Rio Grande do Norte (UFRN), ministrada pela Prof ${ }^{a}$. Dr ${ }^{a}$. Maria Aparecida Pontes da Fonseca, no período 2010.1.

${ }^{2}$ Bolsista do Programa de Educação Tutorial (PET) de Geografia da UFRN.
} 
greve, pressão para reajustes salariais e leis trabalhistas mais rígidas e que beneficiassem o empregado. O papel do Estado foi importante para controlar os ciclos econômicas e as sucessivas crises, também atuou através de políticas fiscais e monetárias, e através de investimentos em transporte, equipamentos públicos, salário social, seguridade social, assistência médica, educação, habitação, garantindo acordos salariais e direitos dos trabalhadores. Essa atuação do Estado segue as idéias do Estado provedor do bem-estar social de Keynes, recebendo em troca a instalação de fábricas garantindo também o emprego para a classe trabalhadora. O Estado também ajuda essas empresas em momentos de crise econômica.

Em termos internacionais o fordismo provocou também a criação do Plano Marshall após a Segunda Guerra, no qual o Estado norte-americano investiu fortemente nas economias de países destruídos pela Guerra como Japão e Alemanha. Assim, esses e outros países recebiam os excedentes da produção dos Estados Unidos. Países do mundo inteiro abrem-se comercialmente para as grandes potencias mundiais vencedoras da Guerra, ofertando matériaprima, e os países subdesenvolvidos recebiam produtos industrializados dos países desenvolvidos. Provocando uma nova Divisão Internacional do Trabalho.

A idéia de desenvolvimentismo trazido com o fordismo promoveu na verdade a destruição das culturas locais, a opressão e dependência para com os países desenvolvidos. Esse modelo de desenvolvimento estagnou a sociedade das ex-colônias, no qual poucos conseguiram fatias do "bolo" de desenvolvimento.

Em linhas gerais o processo de produção fordista se caracterizava pela produção em massa de bens homogêneos, uniformes e padronizados, com grandes estoques e inventários, testes de qualidade, detectando tardiamente erros e produtos defeituosos, ocultando-os nos estoques, perda de tempo de produção por causa de longos tempos de preparo, peças com defeito, pontos de estrangulamento nos estoques, e a redução de custos se dava através do controle dos salários.

No que se caracteriza pelo trabalho o fordismo o trabalhador desenvolvia apenas uma tarefa, o pagamento era baseado em critérios de definição do emprego, com alto grau de especialização das tarefas, pouco ou nenhum treinamento no trabalho, organização vertical do trabalho, ou seja, uma hierarquia sólida, não existia uma experiência de aprendizagem para o trabahador, com ênfase na redução da responsabilidade do trabalhador, disciplinando a força de trabalho, sem nenhuma segurança no trabalho.

O Estado atuava como regulador, de forma rígida, através da negociação coletiva, socializando o bem-estar social, estabilizando a economia internacional através de acordos 
multilaterias, sendo centralizador, intervindo de forma indireta nos mercados através de políticas de renda e de preços, políticas regionais e nacionais, com pesquisa e desenvolvimento financiados pelas firmas e a inovação era liderada pelas grandes indústrias. Ideologicamente o fordismo provoca o consumo em massa de bens duráveis, a idéia da sociedade de consumo, do modernismo, da socialização, da totalidade, e de uma reforma estrutural.

Para nós geógrafos, cabe sabermos quais as consequiências espaciais advindas com o fordismo no qual Harvey destaca a especialização funcional através dos processos de centralização e descentralização, a divisão espacial do trabalho, a homogeneização dos mercados de trabalho regionais, segmentação espacial dos mercados de trabalho, com uma distribuição em escala mundial de componentes e subcontratantes. Lembrando que essa idéia fordista não atingiu todos os lugares do mundo, e em muitos lugares ela ainda é aplicada.

Após a crise mundial do petróleo em 1973 o fordismo e o keynesianismo mostram suas fragilidades, incapazes de conter as contradições capitalistas. Os problemas foram causados pela rigidez dos investimentos de capital fixo, a inflexibilidade do planejamento, rigidez dos mercados, rigidez do Estado em investimentos sociais, provocando as inflações, rigidez dos contratos de trabalho, seguidos de ondas de greve, problemas trabalhistas. Segundo Harvey o sistema capitalista estava entrando em decadência devido ao excesso de fundos, poucas áreas produtivas, forte inflação, crise mundial dos mercados imobiliários, dificuldades das instituições financeiras, aumento do preço do petróleo, exportações de petróleo embargadas para o Ocidente, instabilidade dos mercados financeiros mundiais, crise fiscal, ociosidade de fábricas e equipamentos.

Assim, as empresas viram-se obrigadas a entrar em um período de racionalização, reestruturação e intensificação do controle do trabalho, através da mudança tecnológica, da automação, da busca por novas linhas de produtos, nichos de mercado, provocando a dispersão geográfica das empresas através da zonas de controle do trabalho, provocando também fusões. A década de 1970, e principalmente a década de 1980, foi um período de reestruturação econômica e reajustamento social e política em diversos países do mundo. Esse fenômeno o autor vai denominar de acumulação flexível, e se diferencia da rigidez do fordismo.

Ocorrendo, então, a partir desse período a flexibilidade dos processos de trabalho, dos mercados de trabalho, dos produtos, dos padrões de consumo, com novos setores de produção, novas maneiras de fornecimento de serviços financeiros, com novos mercados, com inovação comercial, tecnológica e organizacional. Os empregadores passaram a exercer uma maior 
pressão do controle do trabalho, ocorrendo o enfraquecimento do sindicalismo da classe trabalhadora, aumentando o desemprego nos países desenvolvidos, desemprego estrutural, ocasionado pelo avanço tecnológico, destruindo e reconstruindo habilidades, tendo o trabalhador ganhos modestos de salários.

O mercado de trabalho passou por essa radical reestruturação devido a volatilidade do mercado, o aumento da competição e o estreitamento das margens de lucro. Assim os grandes capitalistas aproveitaram o enfraquecimento do poder sindical, a grande quantidade de mãode-obra excedente, para fazer regimes e contratos de trabalho mais flexíveis, reduzindo, assim, o emprego regular, e aumentando o emprego em tempo parcial. Passando-se a valorizar o trabalho doméstico, artesanal, familiar, patriarcal, e paternalista, que ressurgem como peças centrais para a produção, terceirização de serviços, e com o crescimento do circuito inferior da economia e do mercado informal. Assim, "As economias de escala buscadas na produção fordista de massa foram substituídas por uma crescente capacidade de manufatura de uma variedade de bens e preços baixos em pequenos".

No lugar das economias de escala foram implantadas as economias de escopo, a produção em pequenos lotes, com subcontratação, acelerando o ritmo de inovação do produto, explorando nichos de mercados altamente especializados, em pequena escala. $\mathrm{O}$ tempo de giro da produção, circulação, distribuição e consumo foi reduzido pelo desenvolvimento tecnológico, das novas formas organizacionais, e do gerenciamento de estoques, a idéia do just-in-time.

A redução do tempo de giro do consumo foi reduzida também através da diminuição da meia vida dos produtos, ocorrendo uma obsolescência artificial através da tecnologia. Assim, um produto comprado este ano próximo ano já não será mais o melhor produto, pois, já será construída uma nova tecnologia, que provocará o consumidor a comprar o novo produto. $\mathrm{O}$ autor vai denominar essas novas estruturas de pós-modernidade, pois é celebrada a diferença, a efemeridade, o espetáculo, a moda e a mercadificação de formas culturais.

Alguns autores denominam esse novo período de pós-moderno. Outros denominam esse período de meio técnico científico informacional. Portanto, somos levados a pensar que acumulação flexível, pós-modernidade e meio técnico cientifico informacional são denominações diferentes para um mesmo fenômeno que ocorre a partir da década de 1970 no qual modifica a relação espaço-tempo, tornando os tempos escassos e as distâncias (espaços) encurtadas.

O processo de produção na acumulação flexível ocorre através de pequenos lotes, de uma variedade de tipos de produtos, sem estoques, controle de qualidade durante o processo, 
com a detecção imediata dos erros e rejeição de peças com defeitos, redução do tempo perdido, sendo uma produção voltada para a demanda, com subcontratação, com aprendizagem na prática integrada ao planejamento a longo prazo. O trabalho se caracteriza por múltiplas tarefas, com pagamento pessoal, através de bonificações e gratificações, eliminando a demarcação de tarefas através de um sistema horizontal, com longo treinamento no trabalho, com aprendizagem no trabalho, e ênfase na co-responsabilidade do trabalhador, com segurança no emprego para trabalhadores centrais, e sem segurança para os contratados temporariamente.

O Estado passa a atuar na desregulamentação e regulamentação, com flexibilidade, com negociações locais ou por empresas, com privatização das necessidades coletivas e da seguridade social, com crescentes tensões geopolíticas, descentralização e aumento da competição interregional, interurbana, e intraurbana. O Estado passa a atuar em mercados através de aquisição, com pesquisa e desenvolvimento financiado pelo Estado, e inovação liderada pelo Estado. O papel do Estado se baseia no neoliberalismo que foi mostrado ao mundo através das políticas de Reagan e Thatcher, e disseminaram-se pelo mundo, no Brasil essas políticas neoliberais foram iniciadas por Fernando Collor, e seu auge ocorreu no governo de Fernando Henrique Cardozo. Um dos lemas do neoliberalismo é a não intervenção do Estado, mas os diversos pontos ditos anteriormente mostram ainda um importante papel do Estado para o desenvolvimento das políticas neoliberais.

Ideologicamente a acumulação flexível prega o individualismo, a sociedade como espetáculo, a especificidade, a adaptação a tudo e a todos, denominada de pós-modernismo. Para a Geografia é importante estudar os efeitos espaciais causados por essa acumulação flexível, pela pós-modernidade. Harvey aponta algumas dessas conseqüências, a saber: a agregação e a aglomeração espaciais, a integração espacial, ou seja, a formação de contigüidades e nós. Harvey também aponta a diversificação do mercado de trabalho, através de uma segmentação interna; e uma proximidade, ou integração espacial das firmas verticalmente.

O advento da acumulação flexível não acabou com a produção fordista como uma descontinuidade, a produção fordista continua a ser empregada em diversos lugares do mundo, juntamente com a produção flexível, mostrando a contradição, e os meios que o capital empresarial se utiliza para se chegar ao seu mais importante prêmio, o lucro. 